\title{
La generalización de vocês en el portugués europeo continental y su patrón de difusión geográfica
}

\author{
Víctor Lara Bermejo \\ Universität Bern, Suiza
}

\begin{abstract}
RESUMEN
La generalización de vocês como único pronombre de segunda persona del plural en el portugués europeo no ha despertado el interés de otros fenómenos. Se sabe que apareció en el siglo XVIII, pero carecemos de una investigación pormenorizada de este tema y de las discordancias de persona que se manifiestan dentro de esta innovación. Aunque actualmente este fenómeno represente el uso estándar, la distinción diafásica mediante dos pronombres, dependiendo de la situación comunicativa, aún se atestigua en las zonas más septentrionales de Portugal. El Atlas lingüístico de la Península Ibérica, elaborado a mediados del siglo XX, el corpus sociolingüístico Cordial-Sin, recogido en la década de 1990 y un nuevo trabajo de campo llevado a cabo en 2013 proporcionarán suficiente información para descubrir qué comportamiento lingüístico posee el fenómeno, así como su extensión geográfica y su patrón de difusión.
\end{abstract}

\begin{abstract}
The generalisation of vocês as the only second person plural pronoun in European Portuguese has not drawn as much attention as other grammatical phenomena. It is known to have appeared in the 1700s, but the literature lacks an exhaustive research on this topic and the person disagreements attested within this innovation. Although nowadays this phenomenon represents the standard usage, the diaphasic distinction by means of two pronouns, depending on the communicative situation, is still attested in the most northern parts of Portugal. The Linguistic Atlas of the Iberian Peninsula, elaborated in the middle of the twentieth century, the sociolinguistic corpus Cordial-Sin, collected in the 1990s and new fieldwork carried out in 2013 will provide enough information to trace the linguistic behaviour of the phenomenon, as well as to map its geographical extension and its diffusion pattern.
\end{abstract}

\section{PALABRAS CLAVE}

Difusión por ondas; portugués europeo; formas de tratamiento; concordancia; geolingüística

\section{KEYWORDS}

Wave model pattern; European Portuguese; forms of address; agreement; geolinguistics

\section{Resumen}

Este artículo trata de descubrir la distribución geográfica y el patrón de difusión de la nivelación de los pronombres de segunda persona del plural ( $2 \mathrm{pl})$ de la variedad europea del portugués y comparar la extensión actual con la que se atestiguaba en el siglo XX. 
La generalización de una forma pronominal (vocês) para tratar a una pluralidad, sin distinción diafásica y en detrimento de la otrora distinción entre pronombre informal vós y formal vocês, no se ha esparcido a todo el país, a pesar de representar la norma. Las gramáticas del portugués, como las realizadas por Cunha y Cintra (1992) o Buzaglo et al. (2013), mencionan que la nivelación no ha llegado a los distritos septentrionales de Portugal (Oporto, Braga o Bragança, como ejemplos), pero Lara (2012) ha demostrado que el Atlas lingüístico de la Península Ibérica (ALPI) presenta dos características principales: su extensión geográfica real y las discordancias de persona entre los elementos con referencia a vocês. El presente estudio revela nuevos hallazgos en la geografía del fenómeno, gracias a un nuevo trabajo de campo, que se resumen a continuación:

(a) Este fenómeno se ha extendido hacia el norte, hasta la isoglosa clásica que divide Portugal en dos áreas. Esta isoglosa se refiere a la trazada por Cintra (1971) que divide el portugués europeo continental en norte y sur. Dicha isoglosa, como veremos más adelante, discurre a la altura de Aveiro, Viseu y Castelo Branco. Además, su difusión geográfica responde al modelo por ondas.

(b) Al igual que para otras innovaciones lingüísticas, no todos los elementos concuerdan sintácticamente. La extensión de la concordancia sintáctica con vocês (la tercera persona del plural: $3 \mathrm{pl}$ ) sigue un continuum implicativo, en el que el reflexivo y los verbos adoptan la innovación antes que los pronombres de objeto. Los posesivos son los últimos elementos en adoptarla.

(c) La ciudad de Lisboa presenta un comportamiento desigual, ya que tan solo ha adoptado hasta cierto punto todas las innovaciones. Esta reticencia se debe a la norma estándar, que prescribe la $3 \mathrm{pl}$ para reflexivos y verbos, pero flexiones de segunda persona de plural $(2 \mathrm{pl})$ a pronombres de objeto y posesivos.

(d) Este fenómeno limita con la región española de Andalucía, que posee una situación sintáctica similar en cuanto a sus formas de tratamiento, y refleja un rasgo lingüístico añadido a todos los que comparten la zona meridional del portugués europeo y el andaluz occidental.

Así, en la sección 1 arriba ('Resumen'), se han resumido los principales hallazgos resultantes de la investigación que se presenta; en la sección 2 ('Introducción'), expongo el sistema pronominal de tratamientos del portugués europeo continental actual, de acuerdo con su variedad estándar; en la sección 3, explico la evolución del uso de la forma de tratamiento en el siglo XX, gracias a dos fuentes: el Atlas lingüístico de la Península Ibérica (ALPI), desde un perspectiva geográfica, gramatical y pragmática, y, posteriormente, muestro los datos del corpus CORDIAL-SIN; en la sección 4, introduzco la metodología empleada para el trabajo de campo que se ha hecho ad hoc para recoger la extensión de la nivelación de vocês y sus concordancias en todos los elementos sintácticos con referencia a dicho pronombre; en la sección 5, analizo los resultados del trabajo de campo y qué novedades aportan desde el punto de vista geográfico, gramatical y pragmático, centrándome en el patrón geolingüístico y comparándolo con la distribución dialectal del portugués europeo continental y la estrecha relación que guarda la zona meridional con el andaluz occidental. Por último, en la sección 6, expongo las conclusiones. 


\section{Introducción}

El sistema de pronombres de segunda persona en el portugués europeo estándar distingue perfectamente el número de interlocutores, pero no el grado de cortesía. De hecho, existen dos pronombres: uno en singular y otro en plural. Además de estos, hay muchas formas nominales para denotar el tipo de deferencia hacia el interlocutor (ver Tabla 1), pero $o$ senhor / a senhora es la más extendida y menos marcada (Cintra 1972).

Solo $t u$ induce flexiones de segunda persona, mientras que los sintagmas nominales y vocês han de concordar en tercera persona. Este es el uso estándar, ubicado tan solo en la zona central y meridional de Portugal y responde a un desarrollo ulterior del paradigma de formas de tratamiento heredado del latín. Antes, el portugués discernía el grado de cortesía mediante dos pronombres distintos tanto en singular como en plural. Tu en singular y vós en plural más concordancia de segunda persona se destinaban a contextos informales, mientras que você en singular y vocês en plural más concordancia en tercera persona se empleaban para contextos corteses (ver Tabla 2).

La falta de distinción con respecto a la situación comunicativa se suele fechar en el siglo XVIII (Cintra 1972; Faraco 1996; Menon 2006), justo el mismo período en que el español hablado en Andalucía eliminó de su paradigma la distinción de dos pronombres en plural a favor de uno solo que servía tanto para la informalidad como para la formalidad (Fernández Martín 2012). Pero, a diferencia del andaluz, el patrón de difusión y el foco geográfico del fenómeno portugués no han sido investigados.

La literatura sobre este fenómeno se encuentra en trabajos de Cintra (1972) y algunas gramáticas del portugués (Vázquez Cuesta y Mendes da Luz 1971; Cunha y Cintra 1992; Brito, et al. 2006; Buzaglo, et al. 2013), y todos ellos afirman que el uso de vós aún está presente en zonas norteñas y rurales del país, considerando esta particularidad arcaica y propia de informantes no letrados. El único empleo de vós que se acepta ampliamente es el que se destina a la retórica, como en discursos militares o religiosos.

Como ya se ha mencionado, vocês (que es sintácticamente de $3 \mathrm{pl}$ ) puede inducir concordancias de $3 \mathrm{pl} \mathrm{y} \mathrm{de} 2 \mathrm{pl}$ incluso en su variedad estándar. Cualquier gramática o manual de portugués como lengua extranjera (siempre y cuando enseñen la variedad europea) constata que los pronombres de objeto y los posesivos concuerdan en $2 \mathrm{pl}$, mientras que los verbos y el reflexivo lo hacen en $3 \mathrm{pl}$ (ver Tabla 3, y ejemplos abajo de (1) a (5)).

Tabla 1. Sistema de formas de tratamiento en el portugués europeo contemporáneo y la concordancia verbal.

\begin{tabular}{|c|c|c|}
\hline & Singular & Plural \\
\hline $\begin{array}{l}\text { Formalidad } \\
\text { Informalidad }\end{array}$ & $\begin{array}{l}\text { O senhor (otros) }+3^{\text {a }} \text { persona } \\
\mathrm{Tu}+2^{\text {a }} \text { persona }\end{array}$ & $\begin{array}{l}\text { Vocês / Os senhores (otros sintagmas nominales) + 3a persona } \\
\text { Vocês + 3a persona }\end{array}$ \\
\hline
\end{tabular}

Tabla 2. Concordancia con las formas de tratamiento del antiguo portugués europeo.

\begin{tabular}{lcc}
\hline & Singular & Plural \\
\hline Formalidad & Você $+3^{\text {a }}$ persona & Vocês $+3^{\mathrm{a}}$ persona \\
Informalidad & $\mathrm{Tu}+2^{\text {a persona }}$ & Vós $+2^{\mathrm{a}}$ persona \\
\hline
\end{tabular}


Tabla 3. Vocês y la concordancia estándar.

\begin{tabular}{lcccc}
\hline Pronombre tónico & Verbo & Reflexivo & Posesivo & Objetos \\
\hline Vocês & $3 \mathrm{pl}$ & $3 \mathrm{pl}$ & $2 \mathrm{pl}$ & $2 \mathrm{pl}$ \\
\hline
\end{tabular}

Tabla 4. Vocês y concordancias en Lara (2012)

\begin{tabular}{lccc}
\hline Pronombre tónico & Verbos & Reflexivos y objetos & Posesivos \\
\hline Vocês & $3 \mathrm{pl}$ & $3 \mathrm{pl} / 2 \mathrm{pl}$ & $2 \mathrm{pl}$ \\
\hline
\end{tabular}

(1) Vocês são irmãos

3PL.NOM. Ser-3PL.PRES.IND. hermanos

('Vosotros sois hermanos')

(2) Vocês estão sempre a se queixar

3PL.NOM. estar-3PL.PRES.IND. siempre a 3PL.REFL. quejar-INF.

('Vosotros siempre os estáis quejando')

(3) Vejo- vos muito apaixonados

Ver-1SG.PRES.IND. 2PL.ACC. muy enamorados

('Os veo muy enamorados')

(4) Dou- vos as chaves

Dar-1sG.PRES.IND. 2PL.DAT. las llaves

('Os doy las llaves’)

(5) Os vossos pais estão a trabalhar

2PL.POSS. padres estar-3PL.PRES.IND. a trabajar-INF

('Vuestros padres están trabajando')

Lara (2012) muestra que la zona centro-septentrional sigue diferenciando por medio de dos pronombres el grado de cortesía en plural: vós más flexiones de 2 pl para la informalidad y vocês más flexiones de $3 \mathrm{pl}$ para la formalidad. Asimismo, el área en la que vós ha desaparecido no concuerda sistemáticamente en $3 \mathrm{pl}$ todos los elementos sintácticos que hacen referencia a vocês. Por ello, vocês puede concordar tanto en $2 \mathrm{pl}$ (pronombres de objeto y posesivos) como en $3 \mathrm{pl}$ (reflexivos y verbos) (ver Tabla 4). El mapa de estas discordancias se muestra más adelante (Mapa 1).

$\mathrm{Al}$ igual que en otros fenómenos, siempre que un cambio lingüístico surge, este no se manifiesta en todos los contextos sintácticos en los que podría (Labov 1966, 1978, 1995; Corbett 2006). El voseo apareció en primer lugar en el pronombre tónico y sus flexiones se han esparcido poco a poco, empezando en el imperativo, siguiendo por el presente de indicativo, posteriormente al presente de subjuntivo y aún no se atestiguan ni en reflexivos, pronombres de objeto ni posesivos (Fontanella de Weinberg 1979; Abadía de Quant 1992; 
Bertolotti y Coll 2003). En el caso de vocês, la 3pl se empleó primero en el pronombre tónico, pero aún no induce concordancia de $3 \mathrm{pl}$ a todos sus elementos sintácticos. Por tanto, es esperable que la $3 \mathrm{pl}$ se extienda gradualmente hasta que se establezca en todas las referencias sintácticas de vocês.

\section{La evolución de vocês en el siglo XX}

A continuación, expondremos el desarrollo de la nivelación en vocês a lo largo del siglo pasado, de acuerdo con los datos manejados en el ALPI y el CORDIAL-SIN.

\subsection{El Atlas lingüístico de la Península Ibérica (ALPI)}

La información más reciente acerca de este fenómeno puede encontrarse en el Atlas lingüístico de la Península Ibérica (ALPI). Este atlas dialectal fue creado por Tomás Navarro Tomás y llevado a cabo por tres equipos repartidos por la zona castellana, la gallego-portuguesa y la catalano-valenciana, con dos investigadores nativos en cada grupo. Se encuestaron 527 enclaves rurales y en cada uno de ellos se entrevistó a un informante con pocos niveles de estudio, que rondara entre los cuarenta y sesenta años y que toda su vida hubiera vivido en el pueblo. Las entrevistas fueron realizadas entre los años 1920 y 1950 y consistían en oraciones y palabras preconcebidas que los informantes repetían en su variedad vernácula y cuyos resultados eran manuscritos fonéticamente de acuerdo con el alfabeto de la RFE (Sanchís Guarner 1962). La metodología puede plantear dudas acerca de la espontaneidad de las respuestas del informante, así como de los escasos datos sobre los fenómenos vernáculos, ya que tan solo se recogía una respuesta por pregunta y se encuestaba a un solo informante por enclave.

Dentro de estas oraciones (subidas en Heap 2003), hay catorce con referencia a una 2pl informal, a saber: ¿Cuándo salís de viaje? (n. ${ }^{\circ} 315$ del cuestionario); Id aprisa (n. ${ }^{\circ} 321$ ); Volved pronto (n. $\left.{ }^{\circ} 324\right)$; Cantad una jota (n. ${ }^{\circ} 323$ ); Decid lo que queráis (n. $\left.{ }^{\circ} 325\right)$; ¿Sois parientes del alcalde? (n. $\left.{ }^{\circ} 336\right)$; Os vais a caer (n. $\left.{ }^{\circ} 341\right)$; Os han engañado (n. $\left.{ }^{\circ} 342\right) ;$ Os queréis callar (n. ${ }^{\circ} 343$ ); Arrodillaos (n. $\left.{ }^{\circ} 344\right) ;$ Bebeos este vaso de aguardiente (n. $\left.{ }^{\circ} 345\right)$; Siéntense ustedes (n. $\left.{ }^{\circ} 364\right) ;$ ¿Adónde camináis? (n. $\left.{ }^{\circ} 410\right)$ (con respuesta doble según el grado de cortesía: formal o informal) y Lo queréis para vosotros (n. ${ }^{\circ}$ 411) (con respuesta doble según el grado de cortesía: formal o informal). Estas proporcionan, como se ve, datos sobre el pronombre tónico, el reflexivo, el acusativo, así como verbos en imperativo y presente de indicativo. Gracias a este trabajo, se ha podido sacar a la luz datos sobre este fenómeno, de acuerdo con tres parámetros: su difusión geográfica, su comportamiento gramatical y su incidencia pragmática.

\subsubsection{Distribución geográfica}

En términos geográficos, este fenómeno se atestiguaba en el centro y sur de Portugal, concretamente en los distritos de Faro, Beja, Setúbal, Évora, Portalegre, Lisboa, Santarém, Leiria y Coimbra. A pesar de los resultados, no fue posible averiguar el patrón de difusión, ya que no había suficientes datos. Sin embargo, el hecho de que hallemos fases con un menor número de innovaciones en áreas aisladas induce a pensar que el fenómeno seguía un modelo por ondas, como describen Chambers y Trudgill (1980) o Wolfram y Schilling-Estes (2003). Este modelo predice que un fenómeno lingüístico aparece en un punto geográfico, llamado foco o epicentro, en el cual aparecerán todas las innovaciones que el fenómeno produzca. Al mismo tiempo, cada vez que surja una innovación en el foco, este la contagiará 
a su periferia, la cual hará lo mismo a sus zonas colindantes. Solo cuando un área adopta una innovación puede extenderla a su periferia. Si aplicamos esta información al fenómeno de vocês, podemos sacar las siguientes conclusiones, como indica el Mapa 1, creado a partir de los datos del ALPI que se refleja en Lara (2012).

La fase 1 se caracteriza por presentar una extensión de la $3 \mathrm{pl}$ en el sujeto, el verbo y el reflexivo, pero no en el acusativo, que aún mantiene la 2 pl. La fase 2 ha generalizado también la $3 \mathrm{pl}$ en el acusativo, como indican los ejemplos (6), (7) y (8) abajo tomados del ALPI en dicha zona. Hay que indicar que en todo momento nos estamos refiriendo al uso de vocês como forma de intimidad, por lo que los ejemplos que se muestran a lo largo del trabajo (a no ser que se explicite lo contrario) se refieren a contextos de informalidad o intimidad.

(6) Aonde vão vôs?

Adonde ir-3PL.PRES.IND. 3PL.NOM.

(‘¿Adónde vais vosotros?’)

(7) Enganaram- nos

Engañar-3PL-PERF.IND. 3PL.ACC.

('Os han engañado’)

(8) Querem se calar?

Querer-3PL.PRES.IND. 3PL.REFL. callar

(‘Os queréis callar?’)

\subsubsection{Distribución gramatical}

Según el comportamiento gramatical, el fenómeno presume la extensión de la 3pl en todos los elementos sintácticos con referencia vocês. Ya que vocês induce flexiones de 3 pl, estas se esparcirán paso a paso, hasta que se asienten en todos sus contextos sintácticos. De acuerdo con el Mapa 1, la extensión de la 3pl obedece a una jerarquía implicativa representada a continuación (9).

(9) Pronombre tónico / reflexivo / verbo > acusativo

El contínuum muestra que la adopción de la 3 pl en una fase concreta implica su aparición en las fases de su izquierda. Por tanto, si la 3 pl se manifiesta en el acusativo, forzosamente aparece en el reflexivo, el verbo y, por supuesto, en el pronombre tónico. La extensión, por tanto, se desplaza hacia la derecha. Los datos del ALPI mostraron que no existían discordancias de personas entre el pronombre tónico, el reflexivo y el verbo, por lo que se ubican en la misma fase del continuum.

\subsubsection{Distribución pragmática}

Por último, los datos del ALPI, como se ha comentado, presentaban preguntas en un contexto de informalidad, pero había dos (n. 410 y n.o 411$)$ que también se habían formulado para un grupo de interlocutores en un contexto formal. Los resultados pusieron de manifiesto que la concordancia gramatical de los encuestados en el ALPI no cambiaba según el grado 
de cortesía. Aunque podían elegir, aparte de vocês, otras formas de tratamiento (como os senhores o vossemecês), la $3 \mathrm{pl}$ era consistente.

\subsection{Corpus CORDIAL-SIN}

El Corpus Dialectal para o Estudo da Sintaxe (CORDIAL-SIN) es un proyecto cuyo propósito es el estudio de la variación sintáctica dialectal del portugués europeo. Está constituido por extractos de discurso espontáneo y semi-dirigido grabados en 200 enclaves de Portugal en la década de 1990. Estos extractos se han tomado de otros proyectos, como el Atlas linguísticoetnográfico de Portugal e da Galiza (ALEPG), Atlas linguístico do litoral portugués (ALLP), Atlas linguístico e etnográfico dos Açores (AlEAç) o Fronteira dialectal do Barlavento algarvio (BA). La representatividad geográfica del corpus es por tanto importante.

Los datos del CORDIAL-SIN ejemplifican el empleo de la innovación vocês en zonas insulares, así como en los distritos de Aveiro y Viseu (ver ejemplos de (10) a (13)). Este hecho llevó a Lara (2013) a concluir que la presión estándar se había extendido hacia el norte. No obstante, el discurso semi-dirigido no es la situación idónea para recoger flexiones de 2 pl, ya que los entrevistados suelen dirigirse a una sola persona, tienden a hablar de sí mismos o de terceras personas.

(10) Povo, trabalhai [..] Se vocês se virem

Pueblo, trabajar-2PL.IMP. [...] si 3PL.NOM. 3PL.REFL. ver-3PL.FUT.SUBJ.

naufragados, agarrai-vos à terra

naufragados, agarrar-2PL.IMP. 2PL.REFL. a la tierra

('Pueblo, trabajad [...] Si os veis naufragados, agarraos a la tierra')

(Covo, Aveiro)

(11) Eles era para os ouvirem, para

3PL.NOM. ser-3PL.IMPF.IND. para 3PL.ACC. oír-3PL.INF., para

saberem onde vocês estavam

saber-3PL.INF donde 3PL.NOM. estar-3PL.IMPF.IND.

('Estaban para escucharlos, para saber dónde estabais vosotros')

(Granjal, Viseu)

(12) Meus amigos, agora escolhei o que vocês quiserem,

Mis amigos, ahora elegir-2PL.IMP. lo que 3PL.NOM. querer-3PL.FUT.SUBJ.

se quereis à cega

si querer-2PL.PRES.IND. a la ciega

('Amigos míos, ahora elegid lo que queráis, si queréis ciegamente') (Covo,

Aveiro) 
Dejar-2PL.IMP. morir-INF. y después 3PL.NOM. dar-2PL.IMP. 3SG.ACC., vendei- $\quad$ o, dai- $\quad$ o $\quad$ a quem vocês vender-2PL.IMP 3SG.ACC., dar-2PL.IMP. 3SG.ACC. a quien 3PL.NOM. quiserem querer-3PL.FUT.SUBJ.

('Dejad morir y después dadlo, vendedlo, dadlo a quienes queráis vosotros') (Covo, Aveiro)

Cabe destacar en los ejemplos cómo cambia la concordancia según se exprese el pronombre vocês o se omita. Este hecho se ha relacionado con un proceso de cambio lingüístico en marcha, donde una forma compite con otra hasta que una de las dos se establece. En el intervalo en el que ambas son posibles, suelen producirse hibridaciones y alternancias constantes entre las dos formas, provocando discordancias (como en el caso del portugués) (Givón 1975; Corbett 2006). Aunque este hecho merece un análisis exhaustivo, el propósito del artículo es centrarnos en el aspecto geográfico del fenómeno de la nivelación de vocês, por lo que no nos detendremos sobre las razones de esta particularidad lingüística. Así pues, pasamos a describir la metodología empleada en un trabajo de campo específico ante la falta de datos cuantitativos y las carencias de este tipo de recolección.

\section{Metodología}

Ya que los informantes del ALPI eran todos hombres, hemos entrevistado tanto a personas de género masculino como femenino, residentes en el mismo enclave y con edades superiores a los 60 años. Aunque hay ciertas divergencias en el comportamiento lingüístico de hombres y mujeres, nuestro objetivo es mostrar la extensión y difusión geográficas de dicho fenómeno, por lo que centraremos el análisis en este factor. Hemos entrevistado nueve enclaves rurales más la ciudad de Lisboa, tanto en la zona 1 como en la 2 del ALPI (de acuerdo con las zonas resultantes del estudio de Lara [2012]). Asimismo, hemos encuestado tres enclaves más (Tondela, Covilhã y Fundão) que pertenecen a áreas en las que el fenómeno aún no se había manifestado a mediados del siglo XX (ver Mapa 2).

Como hemos apuntado, las concordancias de $2 \mathrm{pl}$ son las que surgen con menos probabilidad en una conversación. Por ello, para compensar las carencias de los cuestionarios con oraciones preconcebidas, se ha pedido a los informantes que interpretaran situaciones de la vida cotidiana, en las que tenían que dirigirse a un grupo de personas. Todas las expresiones (algunas de las cuales exponemos en la Tabla 5) se buscaban de manera indirecta, al estilo de cómo se describe a continuación.

Entrevistador: Imagine que se encuentra con sus nietos y les pregunta cómo están sus padres, ¿cómo lo haría?

Entrevistado: Meninos, como estão os vossos pais?

'Niños, ¿cómo están vuestros padres?' 
Cada situación promovía la aparición de un elemento sintáctico dado (verbo, reflexivo, pronombres de objeto, posesivos, sujeto), con el fin de recoger todas las posibles discordancias. Los datos más recientes se compararán también con los proporcionados por el CORDIALSIN, publicados en Lara (2013). Los mapas resultantes se han confeccionado gracias a la aplicación GabMap, de la Universidad de Groningen (Holanda) (Nerbonne et al. 2011).

\section{Análisis}

A continuación, detallaremos la extensión de este fenómeno, según el elemento sintáctico estudiado.

\subsection{Sujeto / reflexivo / verbo}

El Mapa 3 muestra la extensión de la nivelación de vocês en el sujeto. La zona en blanco indica el área donde aún pervive la distinción diafásica entre vós y vocês, mientras que el color azul oscuro muestra la zona donde vocês se ha impuesto como pronombre también de informalidad. Hay que añadir una pequeña zona en azul claro donde se empiezan a manifestar usos de vocês como informal, aunque en convivencia con vós como también pronombre de informalidad. Asimismo, debemos añadir que los resultados del trabajo de campo no han arrojado discordancias entre sujeto, reflexivo y verbo. Esto significa, como muestra el Mapa 3, que siempre que aparece vós, la 2pl surge en el reflexivo y el verbo, mientras que si el informante produce vocês, también produce la $3 \mathrm{pl}$ en el reflexivo y el verbo.

Igualmente, el Mapa 3 refleja que vocês ya se manifiesta en Aveiro y Viseu, tal y como sugerían los datos del CORDIAL-SIN. Sin embargo, mientras el CORDIAL-SIN daba muestras todavía de la alternancia entre el sistema conservador e innovador, el corpus actual prueba que a día de hoy la innovación se ha establecido por completo (ejemplos de (14) a (16)).

(14) Onde é que vocês se conheceram?

Donde es que 3PL.NOM. 3PL.REFL. conocer-3PL.PERF.IND.

(‘¿Dónde os conocisteis vosotros?’)

$$
\text { Vocês estão a falar mal de alguém }
$$

3PL.NOM. estar-3PL.PRES.IND. a hablar-INF. mal de alguien

('Vosotros estáis hablando mal de alguien')

(16) $\mathrm{Eu}$ quero falar com vocês

1sG.NOM. querer-1sG.PRES.IND. hablar con 3PL.OBL.

('Quiero hablar con vosotros')

En Castelo Branco, de todos los pueblos encuestados, tan solo Covilhã ha producido el nuevo fenómeno, aunque vós sigue presente (17 a 18).

(17) Como estais?

Como estar-2PL.PRES.IND.

(‘Cómo estáis?’) 
(18)
Vocês
estão
bem?

3PL.NOM. estar-3PL.PRES.IND. bien

(‘Vosotros estáis bien?’)

Asimismo, en Covilhã se hallan verbos tanto en $2 \mathrm{pl} \mathrm{y} 3 \mathrm{pl}$, como veíamos en los ejemplos del CORDIAL-SIN, sin duda como muestra de esa pugna entre la solución innovadora (la extensión de vocês al ámbito de la informalidad) y la conservadora (la oposición entre vós - vocês según el grado de cortesía).

\subsection{Pronombres de objeto}

El Mapa 4 muestra la concordancia del acusativo. De acuerdo con el mismo, la zona azul claro presenta morfología de 2pl, frente a la zona azul oscuro, donde los acusativos adoptan morfología de $3 \mathrm{pl}$.

Observamos, pues, que los objetos directos son menos propensos a la $3 \mathrm{pl}$, ya que la zona donde se da es menor que la manifestada por el sujeto. La innovación al extender la $3 \mathrm{pl}$ al acusativo se detiene en Leiria y Coimbra (ejemplos (19) y (20)) y no alcanza el resto del área afectada ni la ciudad de Lisboa, donde los hablantes prefieren seguir el patrón estándar, es decir, la 2pl en los objetos (ejemplos (21) y (22)).

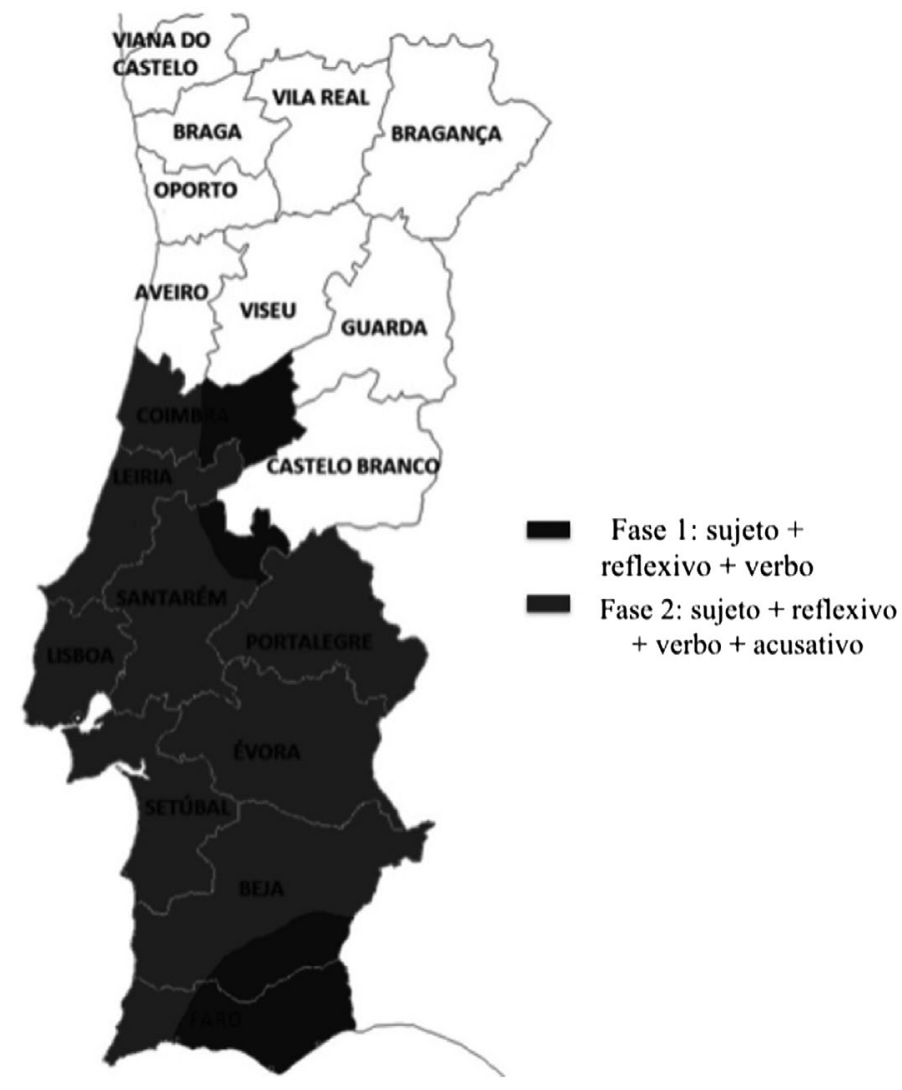

Mapa 1. Vocês y su extensión geográfica en Lara $(2012,88)$ a partir de los datos del ALPI. 


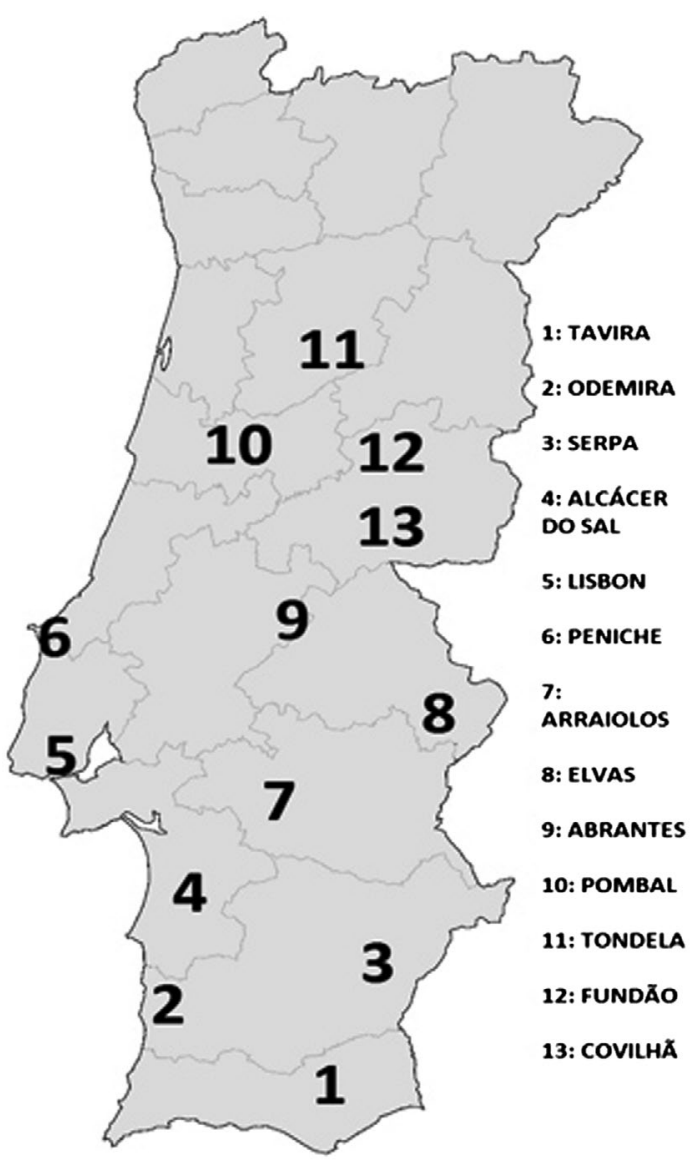

Mapa 2. Enclaves encuestados.

(19) Não os engano

NEG. 3PL.ACC. engañar-1sG.PRES.IND.

('No os engaño')

(20) Vios a passear

Ver-1SG.PERF.IND. 3PL.ACC. a pasear-INF.

('Os vi paseando’)

(21) Ontem vivos

Ayer ver-1sG.PERF.IND. 2PL.ACC.

('Ayer os vi')

(22) Não vos ouvi ontem quando chegaram

Neg. 2PL.ACC. oír-1SG.PERF.IND. ayer cuando llegar-3PL.PERF.IND.

('No os oí ayer cuando llegasteis') 


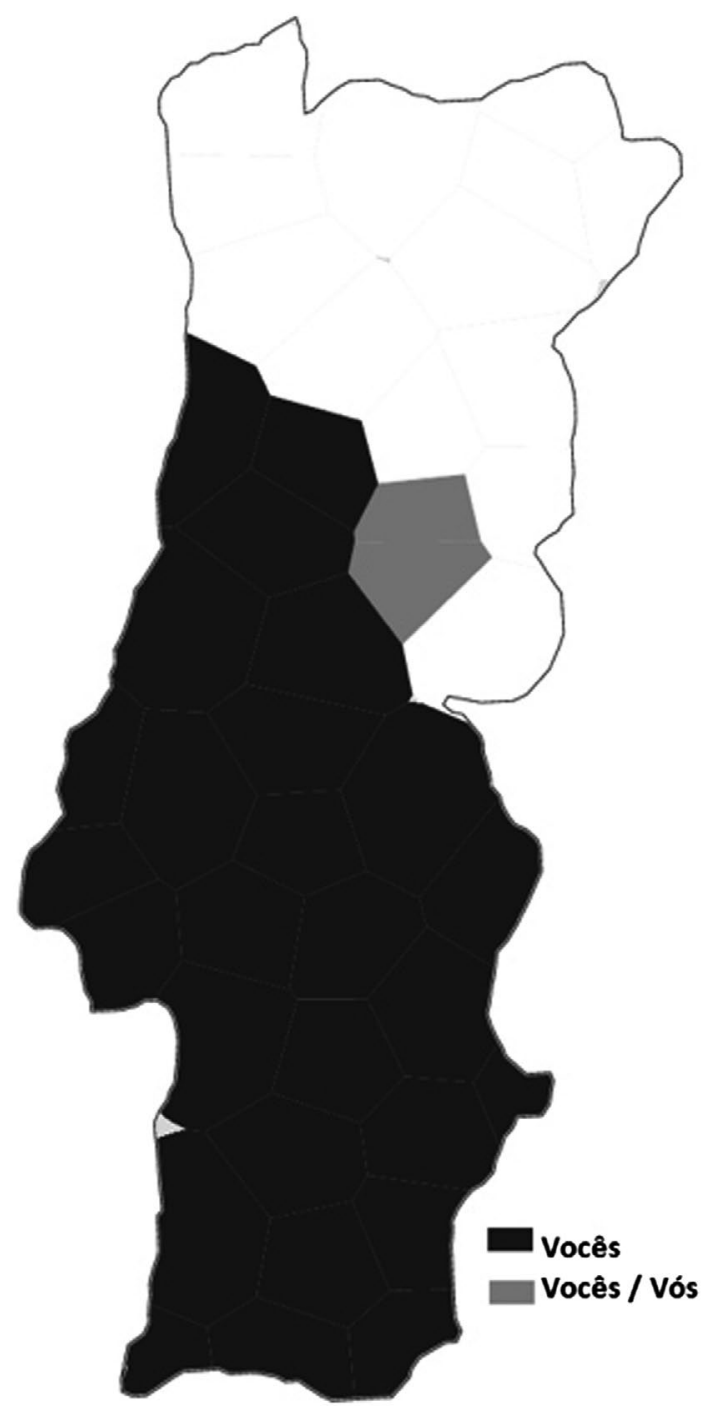

Mapa 3. Sujeto - reflexivo - verbo.

A continuación, describiremos los resultados del dativo (Mapa 5). De nuevo, el azul claro representa morfología de $2 \mathrm{pl} \mathrm{y} \mathrm{el} \mathrm{azul} \mathrm{oscuro,} \mathrm{de} 3 \mathrm{pl}$.

Los objetos indirectos concordados en 3 pl aparecen en una zona aún más acotada. Llegan hasta los distritos de Faro, Beja y partes de Évora y Portalegre. A diferencia de los acusativos, la 3 pl no alcanza zonas centrales y más meridionales (25) a (26), como sí lo hacía el acusativo, permaneciendo en las regiones más sureñas (23) a (24).

(23) Dou- lhes um beijo

Dar-1SG.PRES.IND. 3PL.DAT. un beso

('Os doy un beso') 


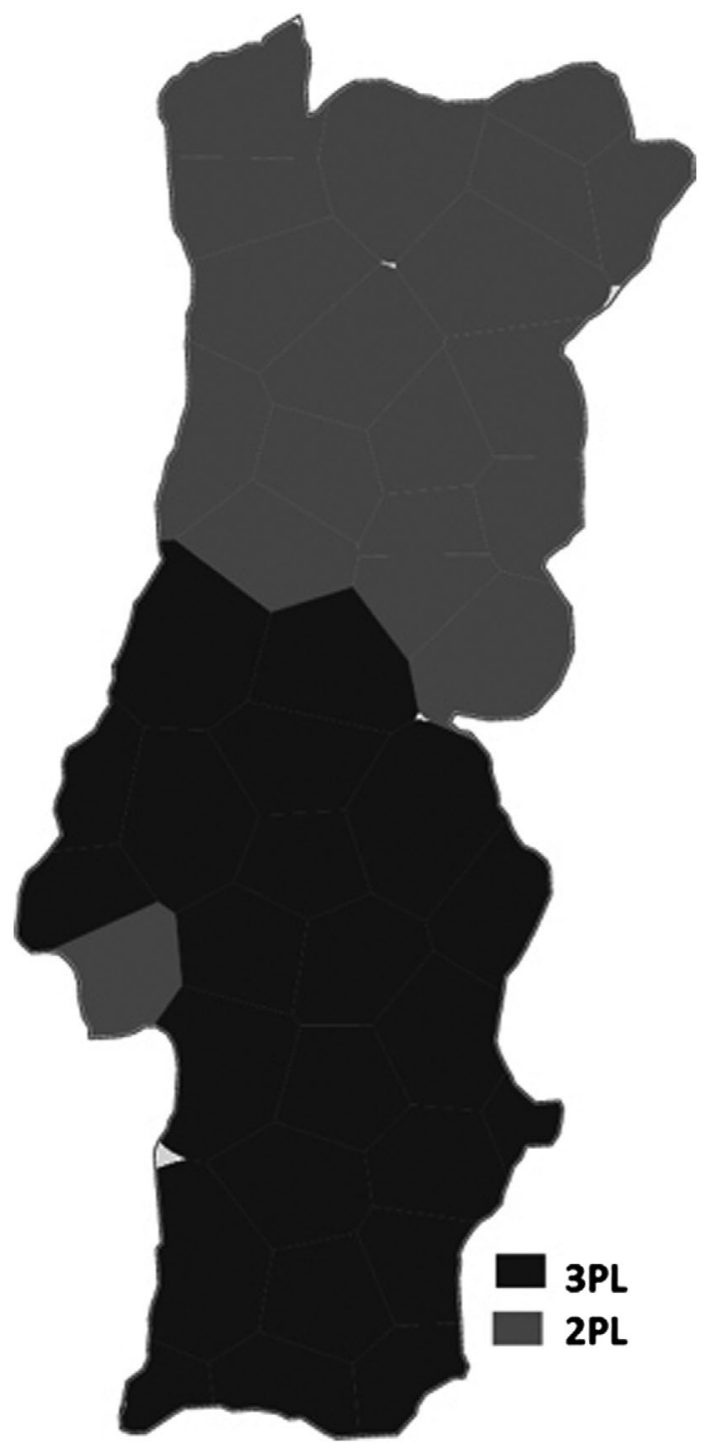

Mapa 4. Acusativo.

Tabla 5. Metodología del trabajo de campo.

\begin{tabular}{ll}
\hline Expresión buscada & Elemento sintáctico buscado \\
\hline Nietos, callaos (vosotros) & Sujeto / reflexivo / verbo \\
¿Queréis (vosotros) café? & Sujeto / verbo \\
¿Os levantasteis (vosotros) ayer tarde? & Sujeto / reflexivo / verbo \\
Ayer os vi pasear & Acusativo \\
¿No os contó mamá anoche un cuento? & Dativo \\
¿Cómo están vuestros padres? & Posesivo \\
\hline
\end{tabular}


Mapa 5. Dativo.

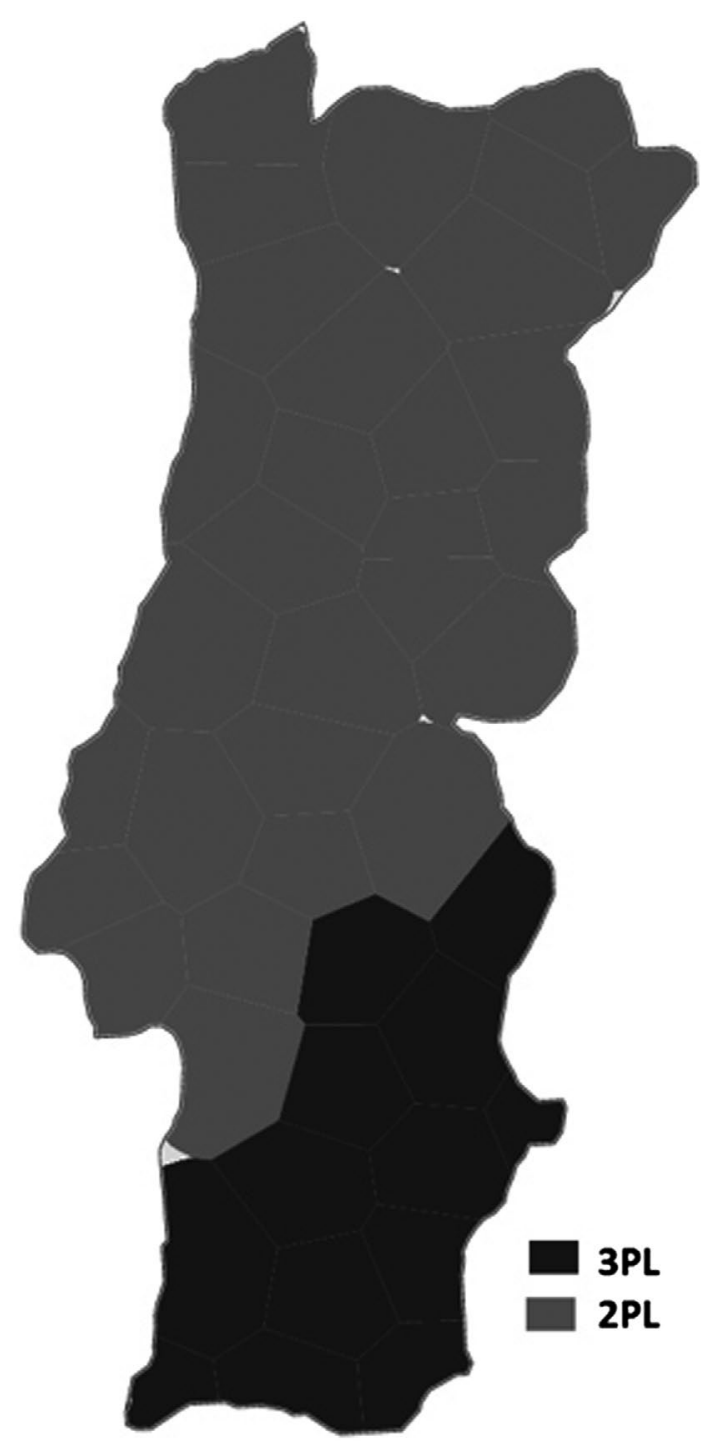

(24) Digolhes uma coisa

Decir-1sG.PRES.IND. 3PL.DAT. una cosa

('Os digo una cosa')

(25) Não vos

digo

nada

NEG. 2PL.DAT. decir-1SG-PRES.IND. nada

('No os digo nada')

(26) Vou

vos telefonar

Ir-1SG.PRES.IND. 2PL.DAT. llamar por teléfono

('Os voy a llamar por teléfono’) 


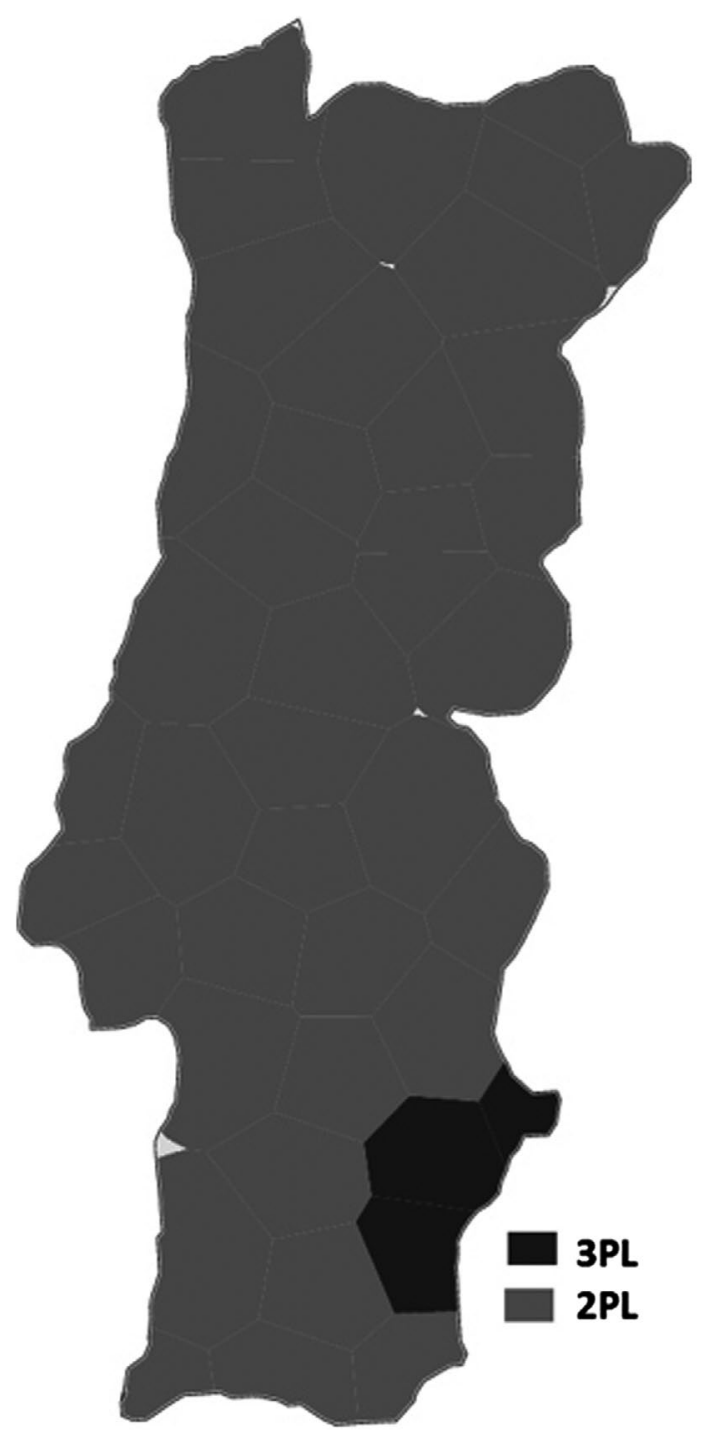

Mapa 6. Posesivo.

\subsection{Posesivos}

Por último, examinaremos la distribución de las formas de posesivo (ver Mapa 6). La zona azul claro muestra morfología de 2 pl y la zona en azul oscuro representa la morfología de $3 \mathrm{pl}$.

La concordancia en los posesivos es hegemónicamente de $2 \mathrm{pl}$. Solo alrededor del enclave de Serpa, en la zona suroriental de Beja, los posesivos empiezan a presentar morfología de $3 \mathrm{pl}$ (27), como la sintaxis de vocês induce, pero el estándar no permite.

(27) Onde estão

os pais de vocês?

Donde estar-3PL.PRES.IND. los padres de 3PL.NOM.

(‘Dónde están vuestros padres?’) 


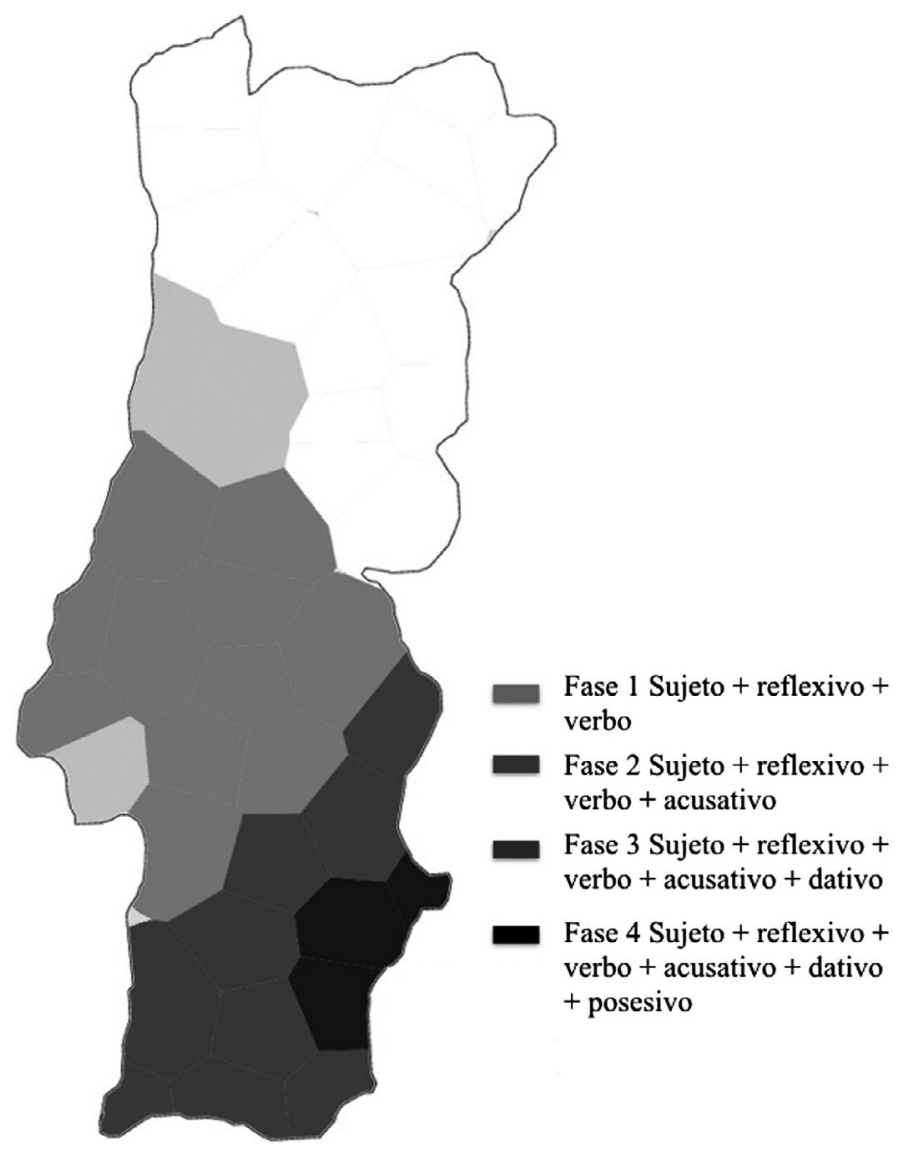

Mapa 7. Patrón de difusión geográfica.

\subsection{Patrón de difusión}

Si analizamos los resultados conjuntamente (Mapa 7), este fenómeno está profundamente asentado en la región suroriental de Beja, en la frontera con España, en concreto, con Andalucía, la misma área donde los pronombres de 2 pl también se han nivelado.

El Mapa 7 muestra de manera sintética el fenómeno de la nivelación en vocês con sus distintas innovaciones, basadas en la extensión de la $3 \mathrm{pl}$ a los diversos elementos sintácticos con referencia a vocês. De acuerdo con el mismo, observamos cuatro fases con una extensión geográfica desigual. En primer lugar, la fase 1 representa el uso de vocês como forma de intimidad y la concordancia del verbo y el reflexivo en $3 \mathrm{pl}$, frente al mantenimiento de la $2 \mathrm{pl}$ en pronombres de objeto y posesivos (28 a 31 ).

(28) Onde é

$$
\text { que vocês se conheceram? }
$$

Donde ser-3SG.PRES.IND. que 3PL.NOM. REFL.3PL. conocer-3PL.PERF.IND.

(‘¿Dónde os conocisteis?’) 
Tabla 6. Nivelación de vocês y extensión de la concordancia de 3pl.

\begin{tabular}{lcccccc}
\hline & Sujeto & Reflexivo & Verbo & Acusativo & Dativo & Posesivo \\
\hline Fase 1 & $3 \mathrm{pl}$ & $3 \mathrm{pl}$ & $3 \mathrm{pl}$ & $2 \mathrm{pl}$ & $2 \mathrm{pl}$ & $2 \mathrm{pl}$ \\
Fase 2 & $3 \mathrm{pl}$ & $3 \mathrm{pl}$ & $3 \mathrm{pl}$ & $3 \mathrm{pl}$ & $2 \mathrm{pl}$ & $2 \mathrm{pl}$ \\
Fase 3 & $3 \mathrm{pl}$ & $3 \mathrm{pl}$ & $3 \mathrm{pl}$ & $3 \mathrm{pl}$ & $3 \mathrm{pl}$ & $2 \mathrm{pl}$ \\
Fase 4 & $3 \mathrm{pl}$ & $3 \mathrm{pl}$ & $3 \mathrm{pl}$ & $3 \mathrm{pl}$ & $3 \mathrm{pl}$ & $3 \mathrm{pl}$ \\
\hline
\end{tabular}

(29) Não vos engano

NEG. 2PL.ACC. engañar-1sG.PRES.IND.

('No os engaño')

(30) Não vos digo nada

Neg. 2PL.DAT. decir-1sG.PRES.IND. nada

('No os digo nada')

(31) Como estão os vossos pais?

Como estar-3PL.PRES.IND. 2PL.POSS. padres

(‘Cómo están vuestros padres?’)

La fase 2 del fenómeno muestra la extensión de la 3 pl también al acusativo, dejando el dativo y el posesivo todavía con morfología de 2pl, como se ilustra en (32 a 35).

Onde é

que vocês se

conheceram?

Donde ser-3SG.PRES.IND. que 3PL.NOM. REFL.3PL. conocer-3PL.PERF.IND.

(‘¿Dónde os conocisteis?’)

(33) Não os engano

NEG. 3PL.ACC. engañar-1sG.PRES.IND.

('No os engaño')

(34) Não vos digo nada

Neg. 2PL.DAT. decir-1sG.PRES.IND. nada

('No os digo nada')

(35) Como estão os vossos pais

Como estar-3PL.PRES.IND. 2PL.POSS. padres

(‘Cómo están vuestros padres?’)

En una fase ulterior (fase 3), el dativo adopta también la 3pl, por lo que en dicha zona tan solo el posesivo es el que se aferra a la morfología de $2 \mathrm{pl}$ (36 a 39). 


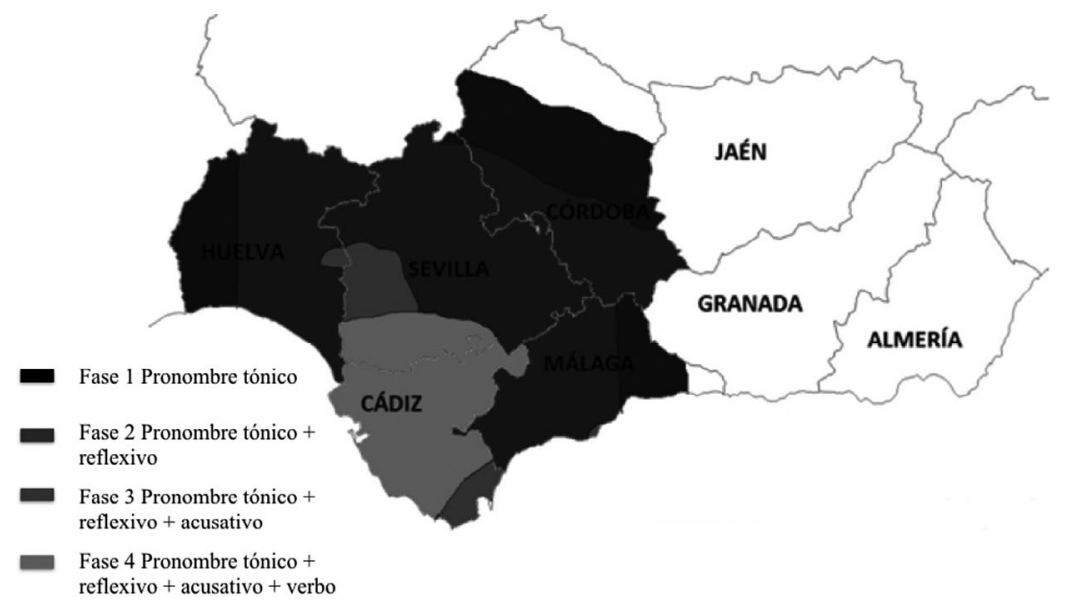

Mapa 8. Nivelación del andaluz y patrón de difusión geográfica en Lara (2012, 85).

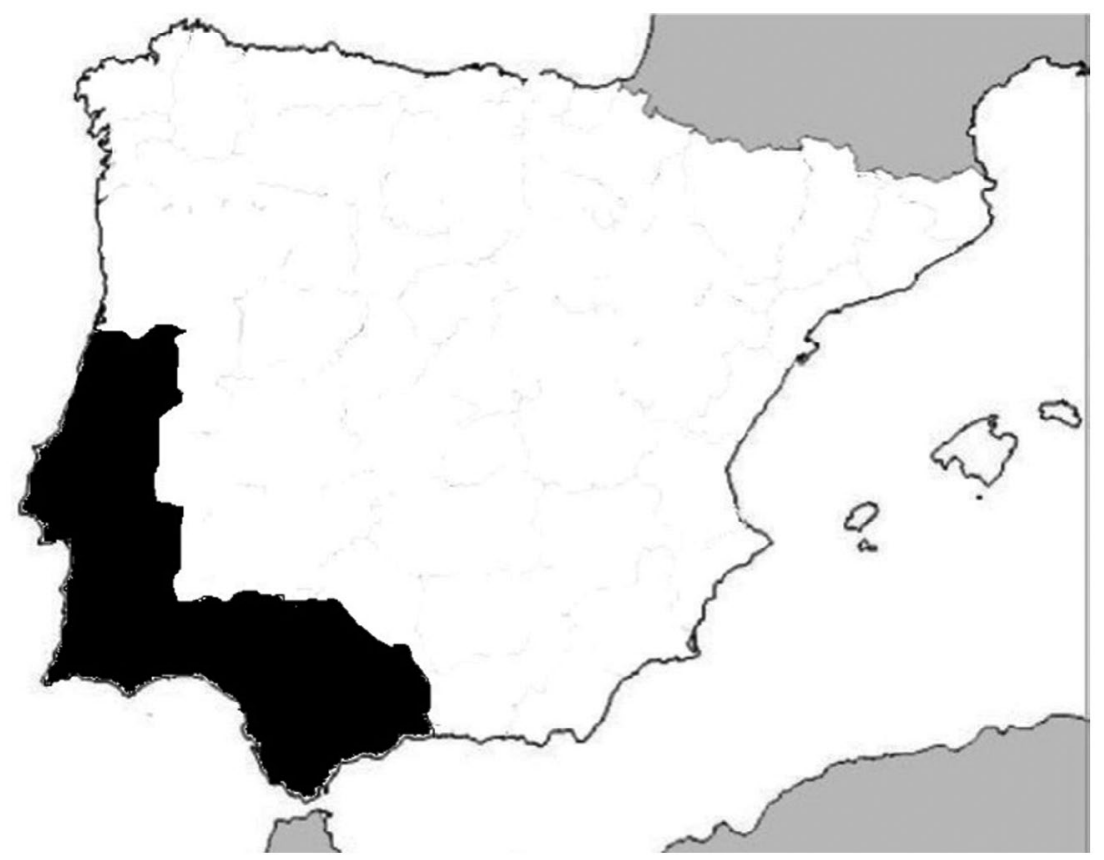

Mapa 9. Extensión geográfica en la Península Ibérica, adaptado de Fernández-Ordóñez (2011).
(36) Onde é
que vocês se
conheceram?

Donde ser-3SG.PRES.IND. que 3PL.NOM. REFL.3PL. conocer-3PL.PERF.IND.

(‘¿Dónde os conocisteis?’)

(37) Não os engano

NEG. 3PL.ACC. engañar-1sG.PRES.IND.

('No os engaño') 


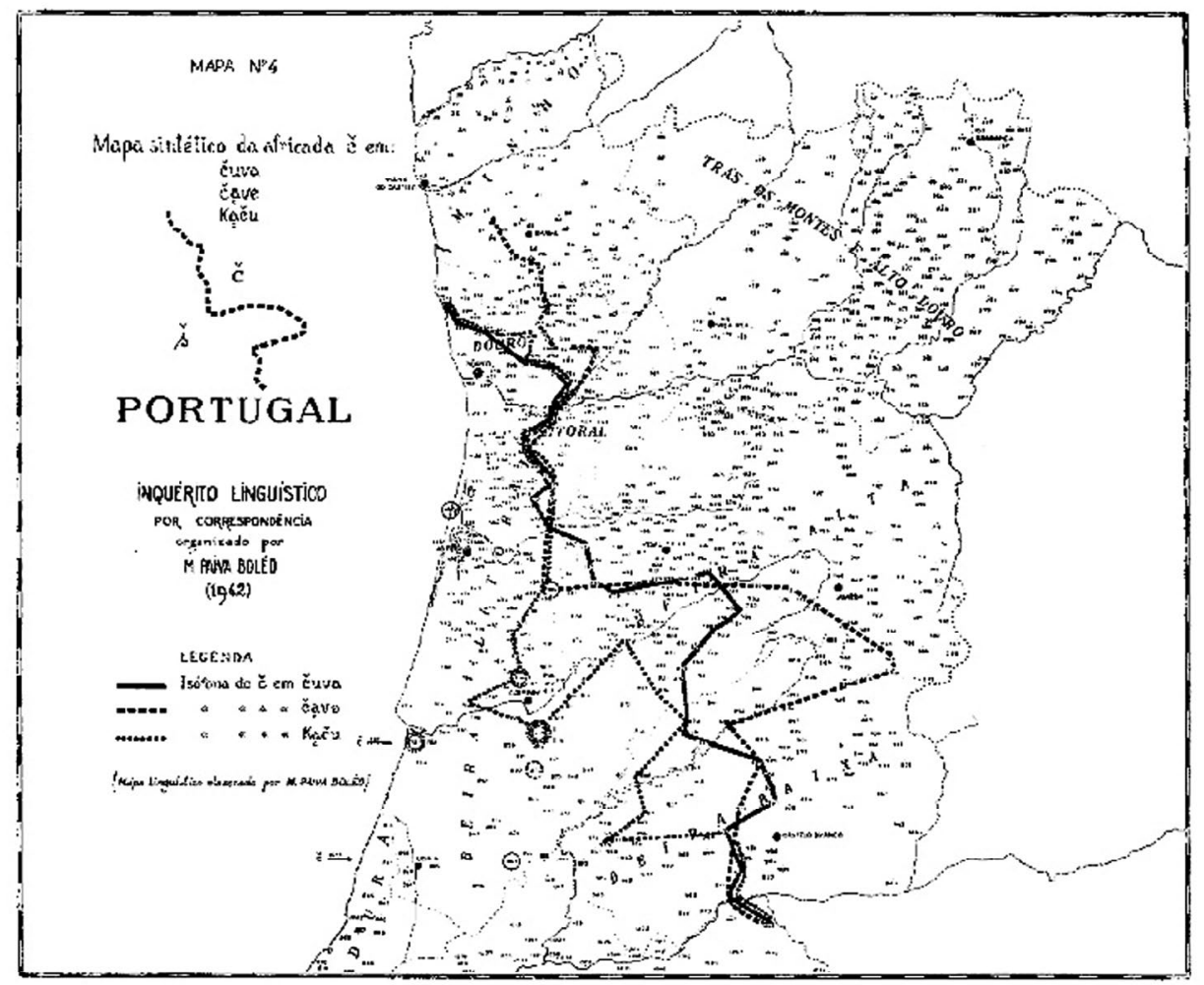

Mapa 10. Isoglosas clásicas del portugués en Boléo $(1950,48)$.

(38) Não lhes digo nada

Neg. 3PL.DAT. decir-1sG.PRES.IND. nada

('No os digo nada')

(39) Como estão

os vossos pais?

Como estar-3PL.PRES.IND. 2PL.POSS. padres

(‘Cómo están vuestros padres?’)

En un último estadio (fase 4), la $3 \mathrm{pl}$ se asienta también sobre el posesivo, terminando con ello su extensión a todos los elementos sintácticos dependientes o con referencia a vocês $(40$ a 43$)$.

(40) Onde é

que vocês se

conheceram?

Donde ser-3SG.PRES.IND. que 3PL.NOM. REFL.3PL. conocer-3PL.PERF.IND.

(‘Dónde os conocisteis?’)

(41) Não os engano

NEG. 3PL.ACC. engañar-1sG.PRES.IND.

('No os engaño') 


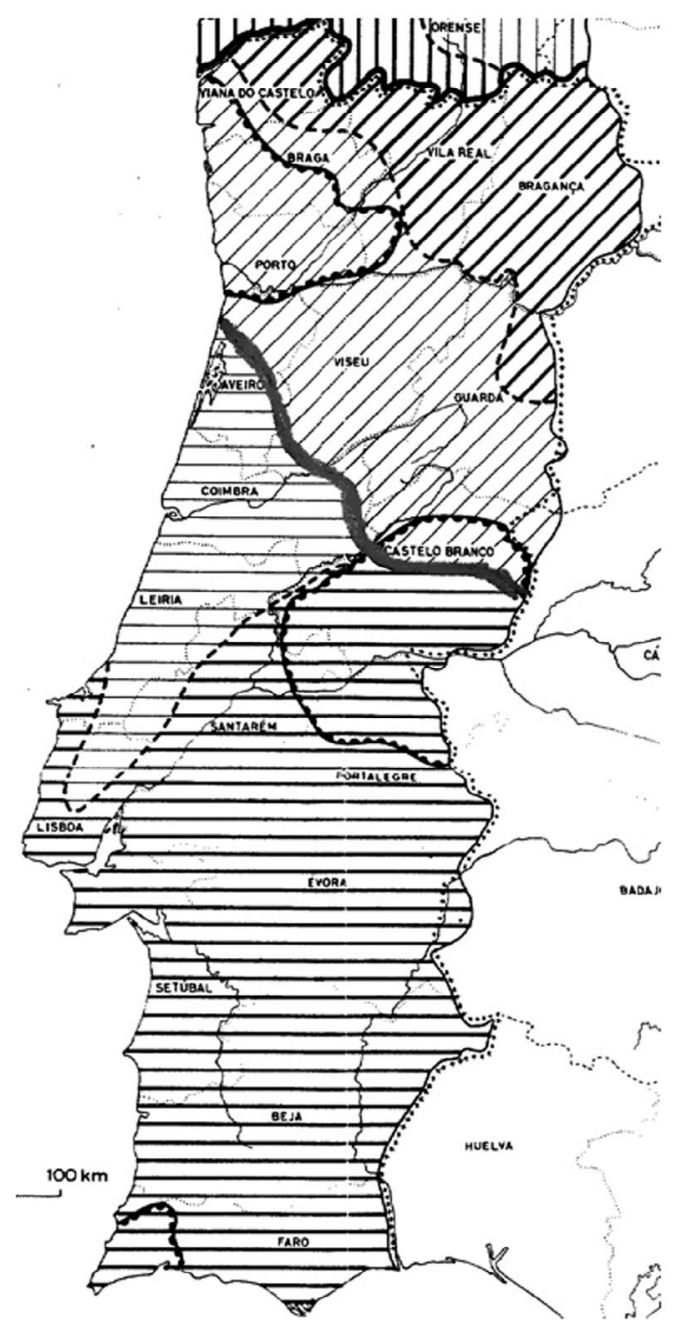

Mapa 11. División dialectal del portugués en Cintra (1971: 98).

(42) Não lhes digo nada

Neg. 3PL.DAT. decir-1sg.PRES.IND. nada

('No os digo nada')

(43) Como estão os pais de vocês?

Como estar-3PL.PREs.Ind. los padres de 3PL.NOM.

(‘Cómo están vuestros padres?’)

Por tanto, si una zona concuerda el posesivo en 3pl, también hará lo mismo en el acusativo, dativo, verbo, reflexivo y, por supuesto, en el sujeto (44).

(44) Sujeto / reflexivo / verbo $>$ acusativo $>$ dativo $>$ posesivo 
En la Tabla 6, se sintetizan las fases del fenómeno, según la extensión de la 3pl en los elementos sintácticos dependientes de vocês:

Observamos que el foco (de donde surgen las innovaciones del fenómeno) se localiza en la frontera con España, alrededor de Serpa, en la zona limítrofe donde el mismo fenómeno se manifiesta para el español (Mondéjar 1974; Alvar 1996; Lapesa 2000; Cano 2004; Penny 2004; Menéndez Pidal 2005; Lara 2010, 2012).

El Mapa 8 representa los estadios del fenómeno español, en el cual el pronombre ustedes se ha nivelado como único pronombre de $2 \mathrm{pl}$, independientemente del grado de cortesía. Como en vocês, su sintaxis induce flexiones de 3 pl, pero los hablantes producen tanto la $2 \mathrm{pl}$ como la $3 \mathrm{pl}$ en los distintos elementos analizados en el ALPI. Si comparamos el Mapa 8 con el Mapa 7, advertimos una difusión geográfica similar, ya que en el fenómeno de la nivelación de ustedes, se han producido 4 fases o innovaciones, también basadas en la generalización de la $3 \mathrm{pl}$ en los elementos sintácticos referidos al pronombre ustedes. Así, la fase 1 generaliza el uso de ustedes en detrimento de la oposición vosotros - ustedes (45 a 46).

(45) Ustedes os vais de viaje

(46) A ustedes os han engañado

La fase 2 extiende la $3 \mathrm{pl}$ al reflexivo, pero en dicha área todos los demás elementos sintácticos (verbo, objetos, etc.) adoptan desinencia de 2pl (47 a 48).

(47) Ustedes se vais de viaje

(48) A ustedes os han engañado

La fase 3 provoca el establecimiento de la 3pl también en el acusativo (49 a 50).

(49) Ustedes se vais de viaje

(50) A ustedes los han engañado

Por último, la fase 4 se caracteriza por inducir la 3 pl, no solo a los elementos señalados anteriormente para las fases previas, sino también al verbo (51 a 52).

(51) Ustedes se van de viaje

(52) A ustedes los han engañado

Los datos del ALPI no ofrecieron, como hemos apuntado, datos de otros elementos sintácticos, como el dativo o el posesivo. De nuevo, el patrón responde a un modelo por ondas, ya que cada innovación nace en un punto concreto y empieza a contagiarse a la periferia. Las áreas más aisladas coinciden con las primeras fases del fenómeno, mientras que cuanto más cercanos al foco, mayores innovaciones comparten las distintas zonas, es decir, más elementos gramaticales concuerdan en 3pl. Ambos fenómenos se representan en el Mapa 9. 
En resumen, el modelo de difusión geográfica del fenómeno portugués sigue el modelo por ondas descrito antes. El mapa resultante refleja una tendencia interesante, ya que este fenómeno se expande desde el sur y tiene su analogía en el andaluz. Ya Fernández-Ordóñez (2011) ha llamado la atención sobre las características lingüísticas que comparten el andaluz occidental y el portugués centro-meridional. De acuerdo con la autora, la voz borrego para denominar la cría de la oveja se extiende por el suroeste del español peninsular y penetra en el sur y centro del portugués europeo continental, en detrimento de la forma norteña cordeiro. Asimismo, la palabra chivo también se da ininterrumpidamente en el oeste del español peninsular junto con el centro y sur del portugués (chibo), o el término mazorca maçaroca comparte una difusión geográfica similar. Es cierto que la división dialectal del portugués europeo continental se ha basado sobre diferencias léxicas y fonéticas. Así, Cintra $(1961,1962)$ separó el centro-norte con el centro-sur, de acuerdo con las diferencias en los vocablos ordeñar o ubre, entre otros, y advirtió que el sur poseía cierta tendencia a difundir innovaciones, aunque no era de forma sistemática. Para Ribeiro (1962), el centro-sur de Portugal fue tierra ocupada por medio de la repoblación, al igual que el sur de España, y ello incentivó las características lingüísticas que observamos hoy día.

Pero Boléo (1950) también apuntó a una división entre centro-norte y centro-sur basada en la fonética. Entre las diferencias, se encuentra la distinta realización fonética de /ch/ (chuva) entre la pronunciación / / o / t / / ver Mapa 10) o la realización de /g/ (gato) entre la pronunciación $/ \mathrm{g} / \mathrm{o} / \mathrm{k} /$. La isófona discurre prácticamente en diagonal desde Aveiro hasta el sur de Castelo Branco, como el fenómeno que nos ocupa.

Asimismo, Cintra (1971) estableció la distinción centro-septentrional y centro-meridional al comparar la realización de la sibilante correspondiente a las grafías /s/ y /ss/. De acuerdo con el autor, la pronunciación septentrional es de carácter ápico-alveolar, mientras que la meridional es predorsodental. Y es precisamente la pronunciación meridional la que coincide con la pronunciación seseante del andaluz occidental. Es actualmente la investigación de Cintra la que se da por válida y, como se observa en el Mapa 11, la línea roja nos guía para delimitar la isoglosa que parte el portugués europeo continental en dos grandes bloques.

Menos espacio ha ocupado la investigación sintáctica en los dialectos portugueses. Nuevos estudios, como el de Carrilho y Pereira (2011), muestran que el sur ha desarrollado innovaciones en el plano morfosintáctico. Así, el portugués actual presenta formas flexionadas de gerundio (que se distribuyen por el sureste) o la perífrasis estar más gerundio en lugar de la construcción estándar estar a más infinitivo. Por tanto, además de diferencias fonéticas y léxicas, los dialectos septentrionales y meridionales parecen presentar también divergencias morfosintácticas como las descritas con anterioridad, entre ellas, la generalización de vocês como forma de intimidad.

Sin embargo, en todas las innovaciones sintácticas expuestas, vemos la reticencia del centro urbano por excelencia, Lisboa, a adoptar innovaciones que contravienen la norma estándar. Aunque se ha aludido a la singularidad de la ciudad de Lisboa (de hecho, Leite de Vasconcelos [1897, 1929], distinguía la variedad lisboeta dentro del subdialecto extremeño, a su vez inserto en el dialecto meridional; también Vázquez Cuesta y Mendes da Luz [1971], que la tildan de ser una variedad aparte que, además, funciona como la variedad normativa), como el cambio fonético de /e/ a /a/ ante consonante palatal (Teyssier 1982), sin olvidar la pronunciación uvular de /r/ frente a la solución vibrante (Barbosa 1983) o la conservación del diptongo ei frente a la tendencia meridional de monoptongarlo en $e$ (Cintra 1983), resulta a priori más pertinente sugerir que el comportamiento conservador de la ciudad responde 
en mayor medida a su demografía. Es decir, según han demostrado Wolfram y SchillingEstes (2003) o Chambers y Trudgill (1980), los centros urbanos concitan el poder político, económico y social de un determinado territorio y es ese poder el que normalmente impone la variedad estándar (Joseph 1987). La no adopción de la 3pl en los pronombres de objeto y el posesivo en la nivelación de vocês por parte de Lisboa sería tan solo una actitud de liderazgo del estándar (que recordemos que induce la 2pl en dichos contextos sintácticos) frente a innovaciones vernáculas de zonas más rurales.

\section{Conclusiones}

El trabajo de campo realizado en 2013 ha hecho posible descubrir la distribución geográfica actual de este fenómeno, así como las fases gramaticales que representa cada innovación. Gracias a ello, podemos concluir lo siguiente:

(a) La nivelación de vocês en detrimento de vós se está extendiendo al norte, en el portugués europeo continental, tal y como representa el patrón estándar. Los distritos afectados son Faro, Beja, Setúbal, Évora, Portalegre, Lisboa, Santarém, Leiria, Coimbra, Aveiro, Viseu y algunas zonas de Castelo Branco. Por otro lado, prácticamente todo Castelo Branco, Guarda, Bragança, Vila Real, Viana do Castelo, Braga y Oporto siguen utilizando el sistema previo, en el que vós más 2 pl se emplea para la informalidad y vocês más $3 \mathrm{pl}$, para la formalidad.

(b) El contínuum gramatical en el que se esparce la $3 \mathrm{pl}$ se representa de la siguiente manera: sujeto / reflexivo / verbo $>$ acusativo $>$ dativo $>$ posesivo. Por tanto, si la $3 \mathrm{pl}$ se atestigua en el dativo, lo hará también en los elementos de su izquierda, ya que la extensión siempre va hacia la derecha.

(c) El foco del fenómeno (aquel que posee la $3 \mathrm{pl}$ en todos los elementos sintácticos) limita con la zona española donde se da el mismo fenómeno (Andalucía occidental). Aunque no podemos probar que la situación del andaluz influyera en la del portugués, ni viceversa, ambas nivelaciones ocurrieron en el mismo período y se caracterizan por los mismos patrones geográficos y gramaticales. Además, el portugués europeo meridional y el andaluz occidental comparten rasgos lingüísticos que van desde lo léxico, a lo fonético y lo morfosintáctico, constituyendo dicha zona una especie de pequeño Sprachbund.

(d) El patrón de difusión geográfica responde al modelo por ondas, que afirma que un fenómeno dado y todas sus innovaciones surgirán en un foco o epicentro, el cual extenderá cada fase a su periferia. En el caso de vocês, el foco se ubica en la zona suroriental del distrito de Beja, alrededor de Serpa, ya que se caracteriza por poseer todas las innovaciones en la extensión de la 3pl. Lisboa, no obstante, se caracteriza por presentar tan solo la fase 1 del fenómeno (ver Mapa 7), como indica la norma estándar (cabe recordar que la norma prescribe la $3 \mathrm{pl}$ en el verbo y reflexivo, y la $2 \mathrm{pl}$ en los demás elementos). Ese estadio gramatical anterior al que se da en el suroeste puede deberse al carácter conservador de Lisboa para ciertos usos lingüísticos; no obstante, nos inclinamos a pensar que, en este caso, la capital ha optado por mantenerse fiel al estándar, dado que son las áreas urbanas las que más se acercan al modelo prestigioso. 


\section{Nota sobre el autor}

Víctor Lara Bermejo es asistente posdoctoral en la Universidad de Berna (Suiza). Sus áreas de interés tanto en docencia como en investigación son la dialectología hispánica y lusa, la sintaxis y la geografía lingüística, con especial interés en la zona iberorromance. Algunas de sus publicaciones más relevantes son Los clíticos de primera persona del plural en las lenguas peninsulares: una visión dialectal (2015), Quão cortês é você: o pronome de tratamento você no portugués europeu (2015), When agreement is for covert but not for overt: the case of ustedes plus second person plural inflections in Peninsular Spanish (2016) o Labile verbs in Peninsular Spanish: a vernacular phenomenon barely researched (2016).

\section{Bibliografía}

Abadía de Quant, I. 1992. "La relación pronominal-verbal de segunda persona singular en el español de Corrientes durante el siglo XIX, su comparación con la situación en Buenos Aires." Revista argentina de lingüística 8: 31-46.

Alvar, M. 1996. Manual de dialectología hispánica. Barcelona: Ariel.

Barbosa, J. M. 1983. Études de phonologie portugaise. Évora: Universidade de Évora.

Bertolotti, V., y M. Coll. 2003. "A synchronical and historical view of the tú/vos option in the Spanish of Montevideo". En Linguistic theory and language development in Hispanic languages, editado por S. Montrul y F. Ordóñez, 1-12. Somerville: Cascadilla Press.

de Boléo, M. de P. 1950. Dialectologia e história da língua: isoglossas portuguesas. Lisboa: Centro de Estudos Filológicos.

Brito, A. M., I. Duarte, I. Hub Faria y M. H. Mira Mateus. 2006. Gramática da língua portuguesa. Lisboa: Caminho.

Buzaglo Paiva Raposo, E., M. F. Bachelar do Nascimento, M. A. Coelho da Mota, L. Segura y A. Mendes. 2013. Gramática do português. Lisboa: Fundação Calouste Gulbenkian.

Cano, R. 2004. Historia de la lengua española. Barcelona: Ariel.

Carrilho, E., y S. Pereira. 2011. "Sobre a distribuição geográfica de construções sintácticas nãopadrão em Português europeu”. En Textos seleccionados do XXVI Encontro nacional da Associação Portuguesa de Linguística, editado por A. Costa, I. Falé y P. Barbosa, 125-139. Lisboa: APL.

Chambers, J. K., y P. Trudgill. 1980. Dialectology. Cambridge: Cambridge University Press.

Cintra, L. F. L. 1961. "Une frontière lexicale et phonétique dans le domaine linguistique portugais." Boletim de filologia 20: 31-38.

Cintra, L. F. L. 1962. "Áreas lexicais no território português." Boletim de filologia 20: 273-307.

Cintra, L. F. L. 1971. "Nova proposta de classificação dos dialectos galego-portugueses." Boletim de filologia 22: 81-116.

Cintra, L. F. L. 1972. Sobre "formas de tratamento" na língua portuguesa. Lisboa: Horizonte.

Cintra, L. F. L. 1983. Estudos de dialectologia portuguesa. Lisboa: Sá da Costa.

Corbett, G. 2006. Agreement. Cambridge: Cambridge University Press.

Cordial-Sin: Corpus Dialectal para o Estudo da Sintaxe. Lisboa: CLUL. http://www.clul.ul.pt/english/ sectores/variacao/cordialsin/projecto_cordialsin.php.

Cunha, C. L., y L. F. L. Cintra. 1992. Nova gramática do português contemporâneo. Lisboa: João Sá de Costa.

Faraco, C. A. 1996. "O tratamento você em português: uma abordagem histórica." Fragmenta 13: 51-82.

Fernández Martín, E. 2012. La oposición vosotros/ustedes en la historia del español peninsular (17001931). Granada: Universidad de Granada.

Fernández-Ordóñez, I. 2011. La lengua de Castilla y la formación del español. Madrid: Real Academia Española. 
Fontanella de Weinberg, B. 1979. "La oposición cantes/cantés en el español de Buenos Aires". Thesaurus XXXIV: 72-83.

Givón, T. 1975. “Topic, pronoun and grammatical agreement”. En Topic and subject, editado por C. N. Li, 149-188. Nueva York: Academic Press Inc.

Heap, D. 2003. Atlas Lingüistico de la Península Ibérica (ALPI). London: University of Western Ontario. http://westernlinguistics.ca/alpi/

Joseph, J. E. 1987. Eloquence and power: the rise of language standards and standard languages. London: Blackwell.

Labov, W. 1966. The social stratification of English in New York City. Washington DC: Center for Applied Linguistics.

Labov, W. 1978. Sociolinguistic patterns. Philadelphia: University of Pennsylvania Press.

Labov, W. 1995. Principles of linguistic change. Cambridge: Blackwell.

Lapesa, R. 2000. Estudios de morfosintaxis histórica del español. Madrid: Gredos.

Lara, V. 2010. El uso de ustedes por vosotros en Andalucía occidental. Madrid: Universidad Autónoma de Madrid.

Lara, V. 2012. "Ustedes instead of vosotros and vocês instead of vós: an analysis through the Linguistic Atlas of the Iberian Peninsula (ALPI).” Dialectologia Special Issue 3: 57-93.

Lara, V. 2013. "Vocês por vós en el portugués europeo: un fenómeno en auge”. En Estudios sobre variación sintáctica peninsular, editado por X. Viejo Fernández, 99-123. Oviedo: Trabe.

Leite de Vasconcelos, J. 1897. Mapa dialectológico do continente português, precedido de uma classificação sumária das línguas. Lisboa: Guillard Aillaud et Ca.

Leite de Vasconcelos, J. 1929. "Mapa dialectológico português". Opúsculos IV: 791-796.

Menéndez Pidal, R. 2005. Historia de la lengua española. Madrid: RAE / Fundación Menéndez Pidal. Menon, O. P. S. 2006. "A história de você". En Teoria e análise linguísticas: novas trilhas, editado por R. D. A. Berlinck, M. Guedes y C. Murakawa, 99-160. Araraquara: Cult. Acadêmica.

Mondéjar, J. 1974. El verbo andaluz: formas y estructuras. Málaga: Ágora.

Nerbonne, J., R. Colen, C. Gooskens, P. Kleiweg y T. Leinonen. 2011. Gapmap - A Web Application for Dialectology. Groningen: University of Groningen. http://www.gabmap.nl/.

Penny, R. 2004. Variación y cambio en español. Madrid: Gredos.

Ribeiro, O. 1962. “A propósito de áreas lexicais no território português." Boletim de filologia 21: 77-105.

Sanchís Guarner, M. 1962. "El Atlas lingüístico de la Península Ibérica (ALPI)”. En Trabajos, problemas y métodos. Actas del IX Congreso Internacional de Lingüistica Románica, editado por L. F. L. Cintra y M. P. Boléo, 113-120. Lisboa: Centro de Estudos Filológicos.

Teyssier, P. 1982. História da língua portuguesa. Lisboa: Sá da Costa.

Vázquez Cuesta, P., y M. A. Mendes da Luz. 1971. Gramática portuguesa. Madrid: Gredos. Wolfram, W., y N. Schilling-Estes. 2003. “Dialectology and Linguistic Diffusion”. En The Handbook of Historical Linguistics, editado por B. D. Joseph y R. D. Janda, 713-735. Malden: Blackwell. 